\title{
Marcadores de Ativação Endotelial e Auto-Anticorpos na Artrite Reumatóide
}

\section{Markers of Endothelial Activation and Autoantibodies in Rheumatoid Arthritis}

\author{
Roberto Cordeiro de A. Teixeira ${ }^{(1)}$, Alexandre Gabriel Júnior ${ }^{(2)}$, Maria Cristina De Martino ${ }^{(3)}$, \\ Lourdes Conceição Martins ${ }^{(4)}$, Antonio Carlos Lopes ${ }^{(5)}$, Sérgio Tufik ${ }^{(6)}$
}

\section{RESUMO}

A artrite reumatóide (AR) é uma doença crônica inflamatória, caracterizada pela produção de auto-anticorpos e participação do endotélio vascular em sua patogênese. Objetivos: Analisar a correlação da molécula de adesão intercelular (ICAM-1), o fator de von Willebrand (vWF), o fator reumatóide (FR) e o anticorpo antipeptídeo citrulinado cíclico (anti-CCP) com parâmetros de atividade clínica, laboratorial e alterações radiológicas da AR. Métodos: Em 38 pacientes e 24 indivíduos que não apresentavam artrite reumatóide foram dosados FR, anti-CCP, vWF e ICAM-1 no soro. A atividade da doença foi definida pelo escore do DAS28. O Health Assessment Questionnaire (HAQ) definiu a capacidade funcional, e os critérios revisados do American College of Rheumatology, a classe funcional. Radiografias de mãos e punhos quantificaram o índice de Sharp modificado. Resultados: A idade dos pacientes foi de $52 \pm 12,5$ anos e dos indivíduos que não apresentavam artrite reumatóide, de $49 \pm 9,4$ anos. O tempo de doença foi de $68 \pm 66,6$ meses. O vWF apresentou correlação significativa com o tempo de evolução da doença. Os auto-anticorpos tiveram correlação significativa com o índice de Sharp. A correlação do vWF e a ICAM-1 foi significativa com o DAS-28, mas apenas o vWF se correlacionou com o HAQ e com índice de Sharp. Conclusão: Esse estudo demonstrou que os auto-anticorpos não estão correlacionados com a atividade da doença, mas com seu prognóstico e sua gravidade por meio da relação destes com o índice de Sharp. O vWF apresentou correlação significativa com os parâmetros de atividade e gravidade da doença.

Palavras-chave: artrite reumatóide, fator reumatóide, ICAM-1, anti-CCP, fator Von Willebrand.

\begin{abstract}
Rheumatoid arthritis ( $R A)$ is an inflammatory chronic disease characterized by the production of antibodies and participation of the vascular endothelium in its pathogenesis. Objectives: to analyze the correlation of serum levels of the intercellular adhesion molecule 1 (ICAM-1), von Willebrand factor ( $V W F)$, Rheumatoid factor $(R F)$, and anti-cyclic citrulinated peptide (anti-CCP) with clinical, laboratory, and radiological parameters of RA. Methods: Serum levels of ICAM-1,VWF, RF, and anti$C C P$ were measured in $38 R A$ patients and 24 controls. Disease activity was measured by the DAS-28 score and functional capacity was assessed using the HAQ score. The American College of $R$ heumatism criteria defined the functional class. Hand and fist $X$-rays were analyzed using the Sharp's score. Statistical analysis utilized the chi-square, Student's " $t$ ”, Kolmogorov-Smirnov, and Mann-Whitney tests, as appropriate, as well as the Spearman's correlation coefficient. Results: Age range was from $52 \pm 12.5$ and $49 \pm 9.4$ years-old in $R A$ and controls, respectively. Disease duration range was $68 \pm 66.6$ months. Serum vWF levels had a positive significant correlation to disease evolution, whereas $R F$ and anti-CCP correlated to the Sharp score. Serum vWF and ICAM-I levels correlated to DAS-28, while only vWF correlated with HAQ and Sharp scores. Conclusion: This study shows that RF and anti-CCP autoantibody levels are correlated to disease prognosis rather than activity. Serum vWF levels are positively correlated to both activity and severity parameters of the disease.
\end{abstract}

Keywords: rheumatoid arthritis, rheumatoid factor, ICAM-1, anti-CCP, von Willebrand factor.

\footnotetext{
Recebido em 22/05/07. Aprovado, após revisão, em 15/10/07. Declaramos a inexistência de conflitos de interesse.

1. Professor auxiliar da disciplina de Reumatologia da Universidade Estadual de Ciências da Saúde de Alagoas (UNCISAL), mestrando em Clínica Médica pela Universidade Federal de São Paulo (Unifesp).

2. Professor doutor visitante da disciplina de Clínica Médica da Escola Paulista de Medicina (Unifesp/EPM), coordenador médico da Associação Fundo de Incentivo à Psicofarmacologia (Afip) Medicina Laboratorial

3. Bióloga, coordenadora de Validação e Pesquisa da Afip Medicina Laboratorial.

4. Doutora em Estatística do Núcleo de Estudos em Epidemiologia Ambiental do Laboratório de Poluição Atmosférica Experimental da Faculdade de Medicina da Universidade de São Paulo (USP), professora da disciplina de Saúde Coletiva da Faculdade de Medicina do ABC.

5. Professor livre-docente pela Unifesp/EPM e professor titular da disciplina de Clínica Médica da Unifesp/EPM.

6. Professor doutor titular do Departamento de Psicobiologia da Unifesp/EPM.

Endereço para correspondência: Roberto Cordeiro de A. Teixeira, Rua Prof. Sandoval Arroxelas, 127, ap. 301, Ponta Verde, CEP 57035-330, Maceió, AL. e-mail: roberto-alagoas@uol.com.br
} 


\section{INTRODUÇÃO}

A artrite reumatóide (AR) é uma doença crônica inflamatória e a mais comum das doenças reumáticas auto-imunes ${ }^{(1)}$. Sua prevalência é de, aproximadamente, $1 \%$ da população geral ${ }^{(2)}$, com acometimento de ambos os sexos e predominância no sexo feminino, na proporção de 3-4:1. Ocorre mais na faixa etária dos 30 aos $50 \operatorname{anos}^{(2,3)}$. A evolução da doença caracteriza-se por danos teciduais articulares, podendo causar deformidades nas articulações e incapacidade funcional do indivíduo, com significativo impacto socioeconômico ${ }^{(4)}$.

A patogênese da AR caracteriza-se pela produção de auto-anticorpos. O fator reumatóide (FR) está presente em $70 \%$ a $90 \%$ dos pacientes reumatóides ${ }^{(5)}$. No entanto, o FR está positivo em $33 \%$ dos pacientes na fase inicial da doença, e sua especificidade é de $59 \%$ a $65 \%^{(6,7)}$, podendo ser encontrado em outras condições clínicas. Na AR, o FR, apesar de não ser um marcador para diagnóstico, tem grande importância em relação ao prognóstico. Pacientes com títulos altos e persistentes de FR têm maior gravidade e, portanto, pior prognóstico ${ }^{(5)}$.

O anticorpo antipeptídeo citrulinado cíclico (anti-CCP) tem sido muito estudado quanto à sua importância como marcador para diagnóstico e com grande valor preditivo para o prognóstico na AR. Estudos correlacionam o antiCCP com a progressão erosiva óssea da doença sugerindo que pacientes com altos títulos de anti-CCP possam ter doença mais agressiva e, portanto, pior prognóstico ${ }^{(8)}$. $\mathrm{O}$ anti-CCP pode ser detectado em $25 \%$ dos indivíduos em 1,5 a 9 anos do aparecimento dos primeiros sintomas, e no ano que antecede os sintomas sua sensibilidade aumenta para $52 \%$, indicando a eficiência desses testes em predizer o desenvolvimento futuro da $\mathrm{AR}^{(9)}$.

O endotélio vascular também exerce papel importante na patogênese da AR. Em condições normais, desempenha funções vitais como manutenção da permeabilidade seletiva e da homeostase, regulação do tônus vascular e as reações imunes, controle da síntese de células vasculares de crescimento, síntese de componentes da matriz extracelular e síntese, secreção e metabolismo de outros componentes biologicamente ativos ${ }^{(10)}$. A capacidade de detectar a mínima alteração na pressão arterial, no fluxo sangüíneo, no balanço oxidativo, na coagulação, na inflamação e na ativação do sistema imune permite considerar a célula endotelial como o mais perfeito sensor biológico existente ${ }^{(11)}$. $\mathrm{O}$ endotélio reage às agressões teciduais, sejam de natureza metabólica, física, química ou inflamatória.
A reação induz ao aumento da expressão de moléculas de adesão celular e da permeabilidade vascular, facilitando a mobilização transendotelial de células mononucleares e polimorfomonucleares, assim como a ativação de citocinas e outras células pró-inflamatórias ${ }^{(12)}$.

O vWF é uma glicoproteína secretada no plasma pelas células endoteliais e pelos megacariócitos. Sua função está na adesão e na agregação plaquetária, desempenhando um papel importante na formação de tampão hemostático. Especificamente na artrite reumatóide, o vWF, assim como a ICAM-1, está presente em resposta à inflamação ativa e persistente. A AR não está limitada apenas a uma inflamação articular, mas está presente na parede dos vasos. A disfunção endotelial com a inflamação persistente parece ter um papel importante na iniciação e na propagação da arteriosclerose envolvendo moléculas de adesão, citocinas, enzimas proteolíticas, com conseqüente destruição e também com desestabilização de placas arterioscleróticas, estimulando fatores de coagulação como o $\mathrm{vWF}^{(13,14)}$.

A ICAM-1, proteína produzida pela célula endotelial, medeia a interação de células com a matriz extracelular e desempenha um papel importante no recrutamento e na retenção de células pró-inflamatórias. Sua produção é induzida por citocinas na disfunção do endotélio. A ICAM-1 está envolvida no processo inicial da inflamação e se mantém presente na progressão da sinovite reumatóide ${ }^{(15)}$.

O objetivo do presente estudo foi analisar o perfil da expressão sorológica dos marcadores de disfunção endotelial, ICAM-1 e vWF e os auto-anticorpos, o FR e o anti-CCP, fazendo a correlação dessas variáveis entre si e com parâmetros de atividade clínica, laboratorial e alterações radiológicas pelo método de Sharp modificado em 38 pacientes reumatóides e num grupo-controle de 24 indivíduos.

\section{PACIENTES E MÉTODOS}

\section{CASUÍSTICA}

Participaram do estudo 38 pacientes com idade igual ou superior a 18 anos que preenchiam os critérios de classificação para $\mathrm{AR}$, estabelecidos pelo Colégio Americano de Reumatologia $(1987)^{(16)}$. Foram escolhidos todos os pacientes que freqüentavam o Ambulatório de Reumatologia do Hospital Escola Dr. José Carneiro pertencente à Universidade Estadual de Ciências da Saúde de Alagoas (UNCISAL) em Maceió e que não apresentavam outras 
doenças crônicas. Para o grupo-controle foram selecionados indivíduos saudáveis, pareados em sexo e idade.

O estudo foi aprovado pelo Comitê de Ética em Pesquisa da UNCISAL ( $\mathrm{N}^{\circ}$ 277). Após a ciência do termo de consentimento livre e esclarecido e a assinatura deste, foi preenchido protocolo clínico específico com anamnese e exame físico geral e articular, assim como o questionário de avaliação da qualidade funcional ou questionário de avaliação de saúde (Health Assessment Questionnaire HAQ) ${ }^{(17)}$ validado em português ${ }^{(18)}$.

A avaliação radiográfica de punhos e mãos foi feita por meio de radiografias simples realizadas em posição pósteroanterior. Foram aceitos os exames realizados com diferença de tempo, de até três meses, antes ou depois da coleta do sangue. Os dados obtidos da avaliação das radiografias de cada paciente foram analisados pelo método de Sharp (modificado) $^{(19)}$.

Foram realizados os seguintes exames laboratoriais nos indivíduos que participaram da pesquisa: velocidade de hemossedimentação (VHS), proteína C reativa (PCR), FR, anti-CCP, ICAM-1 e vWF.

A VHS foi realizada pelo método de Westergren com valores de referência, na primeira hora, de 0 a $15 \mathrm{~mm}$ para homens e de 0 a $20 \mathrm{~mm}$ para mulheres. A PCR foi realizada por turbidimetria com valor de referência $<6,0 \mathrm{mg} / \mathrm{L}$. O FR foi realizado por nefelometria, considerados negativos valores abaixo de $40 \mathrm{UI} / \mathrm{mL}$. O anti-CCP foi medido por ELISA, tendo valor de referência $<20 \mathrm{UI} / \mathrm{mL}$. Os valores de medida do anti-CCP de 20 a $39 \mathrm{UI} / \mathrm{mL}$ foram considerados positivos fracos de 40 a $59 \mathrm{UI} / \mathrm{mL}$ positivos moderados e $\geq 60 \mathrm{UI} / \mathrm{mL}$ positivos fortes. A ICAM- 1 foi medida por ELISA e considerado negativo o valor $<306$ $\mathrm{ng} / \mathrm{mL}$. Para medida do vWF, foi usada a técnica de imunoturbidimetria com valor de referência $50 \%$ a $160 \%$.

Para a análise estatística, foi feita a análise descritiva de todas as variáveis do estudo. As variáveis qualitativas foram apresentadas em termos de seus valores absolutos e relativos ${ }^{(20,21)}$. As variáveis quantitativas foram apresentadas em termos de seus valores de tendência central e de dispersão ${ }^{(20,21)}$. Para se verificar a associação entre duas variáveis qualitativas, foi utilizado o teste de qui-quadrado ${ }^{(22)}$. Para compararem-se os dois grupos, foi utilizado o teste $\mathrm{T}^{(20,23)}$ (paramétrico), para as variáveis que apresentaram distribuição normal (teste de Kolmogorov-Smirnov ${ }^{(22)}$ ) e homogeneidade das variâncias (teste de Levene ${ }^{(20)}$ ), caso contrário, foi utilizado o teste U de Mann-Whitney ${ }^{(22)}$ (não-paramétrico).
Para análise de correlação entre variáveis quantitativas (sem distribuição normal), foi utilizado o coeficiente de correlação de Spearman. O nível de rejeição da hipótese de nulidade ou nível de significância estatística foi considerado em $0,05 \%$ ou $5 \%$.

Os testes estatísticos foram feitos usando o software SPSS (Statistical Package for Social Sciences), versão 15.0.

\section{RESULTADOS}

As medidas descritivas dos dados demográficos dos pacientes e controles estão apresentadas na tabela 1 .

TABELA 1

Medida Descritiva dos Dados Demográficos ENTRE A AMOSTRA DE PACIENTES COM ARTRITE REUMATÓIDE E O GRUPO-CONTROLE

\begin{tabular}{lcccc}
\hline Variável & Descrição & Reumatóide & Controle & p \\
\hline Sexo & Feminino & $32(84,21 \%)$ & $21(87,5 \%)$ & \\
& Masculino & $6(15,8 \%)$ & $3(12,5 \%)$ & ns \\
& Fem./Masc. & $5,3: 1$ & $7: 3$ & \\
Raça & Parda & $21(55,30 \%)$ & $15(62,5 \%)$ & \\
& Branca & $15(39,5 \%)$ & $8(33,3 \%)$ & ns \\
& Negra & $2(5,2 \%)$ & $1(4,2 \%)$ & \\
Idade & Mínima & 19 & 30 & ns \\
& Máxima & 81 & 68 & ns \\
Tabagismo & Média \pm DP & $51,97 \pm 12,5$ & $49 \pm 9,36$ & \\
& Sim $(1)$ & $1(2,6 \%)$ & 0 & \multirow{2}{*}{0,001} \\
Tempo de & Não (2) & $37(97,4 \%)$ & 24 & \\
doença & 24 meses & $12(31,58 \%)$ & --- & -- \\
& 240 meses & $13(34,21 \%)$ & --- & \\
\hline
\end{tabular}

(Qui-Quadrado); (Teste T).

No grupo de pacientes com AR, 31 pacientes $(81,6 \%)$ apresentavam dor articular e 35 pacientes $(92 \%)$ tinham rigidez matinal: 11 pacientes até 30 minutos, 14 até uma hora e dez acima de uma hora. No exame físico, $20 \mathrm{pa}$ cientes $(52,6 \%)$ apresentavam articulações com aumento da temperatura cutânea, 21 (55,3\%), articulações edemaciadas, $22(57,9 \%)$, atrofia per articular e 13 pacientes $(34,2 \%)$, seqüela de deformidade causada pela AR. Um paciente $(2,6 \%)$ apresentava um nódulo reumatóide e nenhum paciente apresentou comprometimento de outros órgãos.

Os resultados dos exames laboratoriais realizados nos dois grupos estão apresentados na tabela 2 .

As características dos parâmetros de atividade e gravidade da amostra de 38 pacientes com AR estão apresentadas na tabela 3 .

O FR e o anti-CCP não apresentaram significância estatística com sexo, idade e tempo de evolução da doença 
TABELA 2

DESCRIÇÃO DA MÉDIA E DO DESVIO-PADRÃO DOS RESULTADOS LABORATORIAIS DOS 38 PACIENTES COM ARTRITE REUMATÓIDE E DO GRUPO-CONTROLE

\begin{tabular}{lccc}
\hline $\begin{array}{l}\text { VARIÁVEL } \\
(\text { Média } \pm \mathrm{DP})\end{array}$ & $\begin{array}{c}\text { PACIENTES } \\
(\mathrm{n}=38)\end{array}$ & $\begin{array}{c}\text { Controle } \\
(\mathrm{n}=24)\end{array}$ & $\mathbf{p}$ \\
\hline VHS $\left(\mathrm{mm} / 1^{\text {a }}\right.$ hora $)$ & $37,4 \pm 24,3$ & $9,6 \pm 8,1$ & $<0,001$ \\
PCR $(\mathrm{mg} / \mathrm{L})$ & $14,7 \pm 21,2$ & $5,2 \pm 0,7$ & $<0,001$ \\
FR $(\mathrm{UI} / \mathrm{mL})$ & $316,8 \pm 597$ & $19,6 \pm 3,1$ & $<0,001$ \\
Anti-CCP $(\mathrm{UI} / \mathrm{mL})$ & $97,6 \pm 95,6$ & $5,0 \pm 5,6$ & $<0,001$ \\
VWFF $(\%)$ & $276 \pm 263,3$ & $155,6 \pm 63,2$ & 0,004 \\
ICAM-1 $(\mathrm{ng} / \mathrm{mL})$ & $330 \pm 150$ & $218 \pm 64,23$ & 0,001 \\
\hline
\end{tabular}

(Teste T).

TABELA 3

CARACTERÍSTICAS dos PARÂMETROS DE ATIVIDADE E GRAVIDADE DOS PACIENTES COM ARTRITE REUMATÓIDE

\begin{tabular}{lc}
\hline VARIÁVEL & MEDIDAS \\
\hline HAQ & $1,33 \pm 0,68$ \\
Classe funcional & \\
I & $5(13,2 \%)$ \\
II & $15(39,5 \%)$ \\
III & $14(36,8 \%)$ \\
IV & $4(10,5 \%)$ \\
DAS-28 média \pm DP & $3,74 \pm 1,07$ \\
Sharp: & \\
Índice de pinçamento total & 36 \\
Índice de erosão total & 29 \\
Índice mínimo & 0 \\
Índice máximo & 100 \\
Média \pm DP & $31 \pm 20,8$ \\
\hline
\end{tabular}

$\mathrm{HAQ}=$ Health Assessment Questionnaire; $\mathrm{DP}=$ desvio-padrão. $(\mathrm{p}>0,05)$. Também não houve significância estatística dos auto-anticorpos com o HAQ e com a classe funcional da doença, assim como com o DAS-28, a VHS e a PCR ( $\mathrm{p}>$ 0,05). Em relação ao índice de Sharp, o FR e o anti-CCP, estes apresentaram correlação estatística significante com o índice total de pinçamento mais erosão $>22$. O perfil da correlação dos auto-anticorpos com os parâmetros clínicos e laboratoriais de atividade e gravidade está apresentado na tabela 4.

$\mathrm{O}$ anti-CCP apresentou correlação significativa com o FR $(r=0,637 ; p=<0,001)$. Em relação aos marcadores de disfunção endotelial, vWF e ICAM-1, o FR apresentou significância estatística com os dois marcadores, e o anti-CCP somente com o vWF conforme demonstrado na tabela 5 .

O vWF e a ICAM-1 não se associaram com o sexo e com a idade $(p>0,05)$. A análise estatística demonstrou que o vWF positivo se correlacionou com o tempo de evolução da doença $(\mathrm{p}=0,03)$, com o HAQ $(\mathrm{p}=0,02)$, com o DAS-28 ( $\mathrm{p}=0,02)$, com a PCR $(\mathrm{p}=0,003)$ e com o Sharp $(\mathrm{p}=0,001)$. Os dois marcadores não tiveram associação com a classe funcional. Não houve uma diferença significativa do resultado positivo da ICAM-l entre as classes funcionais $(\mathrm{p}>0,05)$. Esta apresentou significância estatística com DAS-28 ( $\mathrm{p}=0,04)$ e PCR $(0,03)$. Os dois marcadores estavam positivos em $100 \%$ dos pacientes com escore do DAS $\geq 5,2$.

O perfil de correlação do vWF e da ICAM-1 com os parâmetros de atividade e gravidade está na tabela 6 .

\section{TABELA 4}

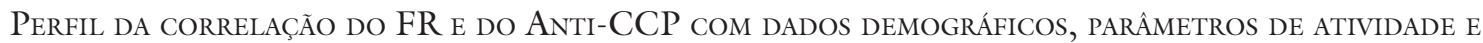
GRAVIDADE NO GRUPO DE PACIENTES COM ARTRITE REUMATÓIDE

\begin{tabular}{|c|c|c|c|c|c|c|}
\hline \multirow{2}{*}{ VARIÁVEL } & \multicolumn{2}{|c|}{$\begin{array}{c}\text { FR } \\
(n=38)\end{array}$} & \multirow{2}{*}{$r-p$} & \multicolumn{2}{|c|}{$\begin{array}{l}\text { Anti-CCP } \\
(n=38)\end{array}$} & \multirow{2}{*}{$r-p$} \\
\hline & $\begin{array}{l}\text { Positivo } \\
(n=23)\end{array}$ & $\begin{array}{r}\text { Negativo } \\
(n=15)\end{array}$ & & $\begin{array}{l}\text { Positivo } \\
(n=24)\end{array}$ & $\begin{array}{r}\text { Negativo } \\
(n=14)\end{array}$ & \\
\hline Idade (anos) & $55,83 \pm 10,76$ & $46,07 \pm 13,00$ & ns & $53,46 \pm 11,85$ & $49,43 \pm 13,60$ & ns \\
\hline TD (meses) & $80,95 \pm 70,61$ & $51,94 \pm 53,03$ & ns & $80,17 \pm 72,21$ & $49,27 \pm 54,02$ & ns \\
\hline HAQ & $1,43 \pm 0,69$ & $1,50 \pm 0,69$ & ns & $1,42 \pm 0,63$ & $1,22 \pm 0,77$ & ns \\
\hline DAS-28 & $3,921 \pm 1,15$ & $3,48 \pm 0,93$ & ns & $3,91 \pm 1,12$ & $3,44 \pm 0,93$ & ns \\
\hline VHS $1^{\text {a }}$ hora & $39,3 \pm 25,50$ & $34,4 \pm 22,90$ & ns & $37,70 \pm 26,6$ & $35,3 \pm 22,50$ & ns \\
\hline PCR & $18,7 \pm 26,40$ & $15,23 \pm 5,86$ & ns & $18,50 \pm 25,80$ & $16 \pm 6,93$ & ns \\
\hline Sharp & $38,35 \pm 21,97$ & $21,90 \pm 14,85$ & 0,$529 ; 0,001$ & $35,70 \pm 21,90$ & $21,64 \pm 15,50$ & 0,$415 ; 0,01$ \\
\hline
\end{tabular}

$\mathrm{n}$ = número de pacientes; $\mathrm{DP}$ = desvio-padrão; FR = fator reumatóide; Anti-CCP = anticorpo antipeptídeo citrulinado cíclico; TD = tempo de doença.

(Spearman) 
TABELA 5

CORRELAÇÃO dO FR E dO ANTI-CCP COM OS MARCADORES ENDOTELIAIS NO GRUPO DE PACIENTES COM ARTRITE REUMATÓIDE

\begin{tabular}{|c|c|c|c|c|c|c|}
\hline \multirow{2}{*}{$\begin{array}{l}\text { Marcadores } \\
\text { endoteliais }\end{array}$} & \multicolumn{2}{|c|}{$\begin{array}{c}\text { FR } \\
(n=38)\end{array}$} & \multirow{2}{*}{$r-p$} & \multicolumn{2}{|c|}{$\begin{array}{l}\text { Anti-CCP } \\
(n=38)\end{array}$} & \multirow{2}{*}{$r-p$} \\
\hline & $\begin{array}{l}\text { Positivo } \\
(n=23)\end{array}$ & $\begin{array}{l}\text { Negativo } \\
(n=15)\end{array}$ & & $\begin{array}{l}\text { Positivo } \\
(n=24)\end{array}$ & $\begin{array}{l}\text { negativo } \\
(n=14)\end{array}$ & \\
\hline $\begin{array}{l}\text { vWF positivo } \\
\text { vWF negativo }\end{array}$ & $\begin{array}{c}17(73,9 \%) \\
6(26,1 \%)\end{array}$ & $\begin{array}{l}6(26,1 \%) \\
9(73,9 \%)\end{array}$ & 0,$649 ;<0,001$ & $\begin{array}{c}19(79,2 \%) \\
5(20,8 \%)\end{array}$ & $\begin{array}{c}4(28,6 \%) \\
10(71,4 \%)\end{array}$ & 0,$422 ; 0,008$ \\
\hline $\begin{array}{l}\text { ICAM-1 positivo } \\
\text { ICAM-1 negativo }\end{array}$ & $\begin{array}{l}13(81,3 \%) \\
10(45,5 \%)\end{array}$ & $\begin{array}{c}3(18,7 \%) \\
12(54,5 \%)\end{array}$ & 0,$528 ; 0,001$ & $\begin{array}{l}12(50 \%) \\
12(50 \%)\end{array}$ & $\begin{array}{c}4(28,6 \%) \\
10(71,4 \%)\end{array}$ & ns \\
\hline
\end{tabular}

(Spearman)

TABELA 6

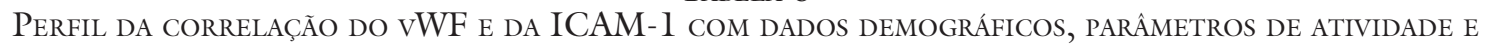
GRAVIDADE NO GRUPO DE PACIENTES COM ARTRITE REUMATÓIDE

\begin{tabular}{|c|c|c|c|c|c|c|}
\hline \multirow{2}{*}{ VARIÁVEL } & \multicolumn{2}{|c|}{$\begin{array}{c}\text { vWF } \\
(n=38)\end{array}$} & \multirow{2}{*}{$r-p$} & \multicolumn{2}{|c|}{$\begin{array}{l}\text { ICAM-1 } \\
(n=38)\end{array}$} & \multirow{2}{*}{$r-p$} \\
\hline & $\begin{array}{l}\text { Positivo } \\
(n=23)\end{array}$ & $\begin{array}{c}\text { Negativo } \\
(n=15)\end{array}$ & & $\begin{array}{l}\text { Positivo } \\
(n=16)\end{array}$ & $\begin{array}{c}\text { Negativo } \\
(n=22)\end{array}$ & \\
\hline Idade (anos) & $55,04 \pm 10,37$ & $47,27 \pm 14,3$ & ns & $55,75 \pm 14,5$ & $49,23 \pm 10,3$ & ns \\
\hline TD (meses) & $89,30 \pm 75,13$ & $35,27 \pm 31,1$ & 0,$340 ; 0,037$ & $75,88 \pm 82$ & $61,57 \pm 52,3$ & ns \\
\hline $\mathrm{HAQ}$ & $9,00 \pm 37,3$ & $1,53 \pm 0,66$ & 0,$355 ; 0,029$ & $1,34 \pm 0,44$ & $9,50 \pm 133,7$ & ns \\
\hline DAS-28 & $4,03 \pm 1,10$ & $3,30 \pm 0,89$ & 0,$374 ; 0,02$ & $4,40 \pm 1,14$ & $3,40 \pm 0,83$ & 0,$338 ; 0,04$ \\
\hline VHS $1^{\text {a }}$ hora & $38,22 \pm 24,60$ & $34,77 \pm 24,50$ & ns & $43,70 \pm 28,47$ & $33,24 \pm 20,61$ & ns \\
\hline PCR & $29,90 \pm 31,24$ & $16,00 \pm 6,90$ & 0,$473 ; 0,003$ & $28,44 \pm 28,60$ & $36,23 \pm 40,22$ & 0,$347 ; 0,03$ \\
\hline Sharp (escore total) & $37,42 \pm 21,73$ & $20,00 \pm 13,70$ & 0,$574 ;<0,001$ & $37,94 \pm 24,83$ & $25,95 \pm 16,02$ & ns \\
\hline
\end{tabular}

$\mathrm{n}=$ número de pacientes; $\mathrm{TD}=$ tempo de doença; $\mathrm{vWF}=$ fator von Willebrand; ICAM-1 = molécula de adesão intercelular; $\mathrm{DP}=$ desvio-padrão.

(Spearman)

Houve uma correlação estatisticamente significante entre vWF e ICAM-1 $(r=0,364 ; \mathrm{p}=0,025)$.

\section{DISCUSSÃO}

A AR é uma doença inflamatória na qual o endotélio exerce um papel importante em sua patogênese. Enquanto o endotélio saudável evita a adesão de células mononucleares, o mecanismo de defesa sob a influência da inflamação induz a expressão das moléculas de adesão que promove a aderência dos monócitos ${ }^{(24)}$. Os estudos demonstram que a inflamação e a ativação endotelial persistente estimulam a produção de fatores homeostáticos endoteliais como $\mathrm{o} \mathrm{vWF}^{(13)}$. A ativação endotelial também exerce papel importante na ativação de células T CD4 e células $\mathrm{B}$ e estimula a produção de auto-anticorpos e a formação de imunocomplexos.
No presente estudo foram analisados o perfil de expressão sérica dos marcadores de disfunção e ativação endotelial ICAM- 1 e vWF e os auto-anticorpos FR e anti-CCP utilizando uma amostra não-probabilística por conveniência na qual todos os pacientes com artrite reumatóide do Ambulatório de Reumatologia do Hospital Escola da UNCISAL no período de outubro de 2005 a dezembro de 2006 entraram para o estudo e em um grupo-controle pareado no sexo e idade com o objetivo de se estabelecer uma correlação com a atividade clínica, laboratorial e alterações radiológicas da doença e avaliar se a presença desses marcadores e os auto-anticorpos estariam relacionados com maior gravidade da doença.

Apesar de a evolução da doença do grupo-reumatóide ser superior a cinco anos ( 68 meses $\pm 66,6$ ), o exame físico desses pacientes demonstra sinais de atividade clínica associados a sinais de cronicidade da doença como a presença de deformidades das articulações. Esses achados foram 
confirmados pelo aumento das provas de fase aguda de inflamação, pelos resultados do DAS-28, pela predominância dos pacientes nas classes funcionais II e III e com o HAQ de $1,33 \pm 0,68$. Esses dados juntamente ao índice total de Sharp para pinçamento mais erosões $31 \pm 20,8$ evidenciam a gravidade da doença nesses pacientes.

Os dois auto-anticorpos estudados apresentaram uma correlação semelhante em relação aos parâmetros de atividade e gravidade da doença. Pesquisas demonstram que a probabilidade diagnóstica aumenta, sensivelmente, em pacientes com FR IgM positivo associado ao anti-CCP positivo $^{(25)}$. O FR IgM e o anti-CCP também se correlacionam e, quando um aumenta, o outro também aumenta na maioria dos pacientes com AR, confirmando a heterogeneidade da etiopatogenia dessa doençça ${ }^{(26,27)}$. Em nossa casuística, os auto-anticorpos não se associaram com atividade da doença, tempo de doença e classe funcional ou HAQ, estando de acordo com a literatura ${ }^{(28,29)}$. Encontramos também uma correlação significativa dos auto-anticorpos com o Sharp, demonstrando que estes são importantes na evolução da doença para a injúria do tecido ósseo e, portanto, predizendo um pior prognóstico.

No presente estudo, a correlação do vWF com os parâmetros de atividade da doença, por meio de correlação significativa com o DAS-28, provas inflamatórias e HAQ, está implicada na inflamação ativa e persistente, demonstrando que, juntamente à ICAM 1 , o vWF pode ser um instrumento a mais para avaliar o perfil de atividade da AR, diferentemente do estudo de Araújo et al ${ }^{(30)}$. A correlação estatisticamente significante com o índice Sharp sugere o valor do vWF como fator preditivo para o prognóstico da AR.

Neste estudo, a ICAM-1 apresentou uma correlação significativa com os principais parâmetros de atividade: VHS, PCR e DAS-28, confirmando os estudos da literatura $^{(31-34)}$, o que atesta a função da ICAM-1 como uma molécula envolvida no recrutamento, na retenção e na migração de células pró-inflamatórias pelo endotélio, portanto, seu aumento reflete doença ativa. No entanto, não houve correlação significativa da ICAM- I com o índice de Sharp, reforçando mais uma vez a relação dessa molécula

\section{REFERÊNCIAS}

1. Bizzaro N, Mazzanti G, Tonutti E, Villalta D, Tozzoli R: Diagnostic accuracy of the anti-citruline antibody assay for rheumatoid arthritis. Clin Chem 47: 1089-93, 2001.

2. Carvalho MAP, Xavier AJD: Artrite Reumatóide. Reumatologia, Diagnóstico e Tratamento. 2.ed. Rio de Janeiro: Medsi, 2001. apenas com a atividade da doença. A ICAM-1 também não se correlacionou com o tempo de doença, visto que a ICAM-1 está relacionada à presença ou à ausência de atividade inflamatória, independentemente do tempo de evolução da doença. A significância estatística encontrada na correlação entre a ICAM-1 e o FR neste estudo, embora isso não esteja descrito na literatura, reflete a diversidade de processos envolvidos na patogênese da AR e comprova a importância da ativação endotelial na produção de autoanticorpos e formação de imunocomplexos.

No presente estudo, observa-se que não houve correlação do FR e do o anti-CCP com parâmetros ligados à atividade clínica e laboratorial nos doentes com AR.

Foi significativa a correlação do FR e do anti-CCP com o índice de Sharp; houve correlação significativa do vWF e da ICAM com PCR e DAS-28; e houve correlação significativa do vWF com o HAQ e o índice Sharp.

Este trabalho reafirma a importância do endotélio na patogênese da artrite reumatóide, tanto na atividade inflamatória e perpetuação desta quanto na gravidade da doença como já demonstrado na literatura. Longe de elucidar o papel da ativação endotelial na AR, o que poderia favorecer o melhor entendimento de vários processos patogênicos específicos e intercorrentes, como lesão vascular e dislipidemias, este estudo abre várias perspectivas investigativas, porém, outros adicionais serão necessários. Do ponto de vista prático para o reumatologista, ainda não podemos aconselhá-lo no sentido de avaliar em seus pacientes marcadores de ativação endotelial. No que diz respeito aos auto-anticorpos, a pesquisa de anticorpos antipeptídeos citrulinados abre, sem dúvida alguma, um caminho importante, não somente para o diagnóstico mais precoce da AR, mas também para a melhor compreensão da etiopatogenia dessa intrigada doença. Neste sentido, como perspectivas futuras, o estudo de outros marcadores como antivimetina citrulinada e modificada (VCM), antígeno que representa melhor o "lócus sinovial", estudos genéticos, no que diz respeito à enzima PAD (peptidio arginina deiminase), bem como os haplotipos HLA $\mathrm{DRB}_{1}$, dentre outros, seriam de grande relevância investigativa $\mathrm{e}$, possivelmente, prática.

3. Alarcon GS: Epidemiology of Rheumatoid Arthritis. Rheum Dis Clin North Am 21: 589-604, 1995.

4. Laurindo IMM, Pinheiro RCG, Ximenes AC, Bertolo MB, et al.: Consenso brasileiro para diagnóstico e tratamento da artrite reumatóide. Rev Bras Reumatol 42: 355-61, 2002.

5. Shmerling RH, Delbanco TL: The rheumatoid factor, an analysis of clinical utility. Am J Med 91: 528-34, 1991. 
6. Wener MH: Rheumatoid Factors. Manual of clinical Laboratory Immunology. Rose NR, et al. (eds.). American Society for microbiology Press: 961-72, 2002.

7. Borretzen M, et al.: Rheumatoid Factor. Autoantibodies, Peter JB, Shoenfeld Y (eds). Elsevier Science BV: 706-15, 1996.

8. Vencovsky J, Machácek S, Sedová L, Kafkova J, et al.: Autoantibodies can be prognostic markers of an erosive disease in early rheumatoid arthritis. Ann Rheum Dis 62: 427-30, 2003.

9. Vossenaar ER, Van Venrooij, WJ: Anti-CCP Antibodies, A Highly Specific marker for (early) rheumatoid arthritis. Clin Applied Immunol Rev 4: 239-62, 2004.

10. Cotron RS, Endothelial Cells, In: Keelley, Harris, Ruddy, Sledger, editors. Textbook of Rheumatology. 3.ed. Philadelphia: WB Saunders: 389-415, 1989.

11. Nascimento CA, Patriarca G, Heimann JC: Estrutura orgânica do endotélio vascular. Endotélio e doenças cardiovasculares 1: 1-16, 2005.

12. Marikovsky M, Ziv V, Nevo N, Herris CC, Mahler O: Cu/Zn superóxido dismutase plays important role in immune response. J Immunol 170: 2993-3001, 2003.

13. Wallberg-Jonsson S, Cvetkovic JT, Sundqvist KG, Lefvert AK, Rantapää-Dahlqvist S: Activation of the immune system and inflammatory activity in relation to markers of atherothrombotic disease and atherosclerosis in rheumatoid arthritis. J Rheumatol 29: 875-82, 2002.

14. Hürlimann D, Enseleit F, Ruschitzka F: Rheumatoid arthritis, inflammation, and atherosclerosis. Herz 29: 760-8, 2004.

15. Klimiuk PA, Sierakowiski S, Latosiewicz R, Cylwik JP, Cylwik B, Skowronski J, Chiwiecko J: Soluble adhesion molecules (ICAM-1, VCAM-1, and E-selectin) and vascular endothelial growth factor (VEGF) in patients with variants of rheumatoid synovitis. Ann Rheum Dis 61: 804-9, 2002.

16. Arnett FC, Edworthy SM, Bloch DA, et al.: The Americam Rheumatism Association 1987 revised criteria for the classification of rheumatoid arthritis. Arthritis Rheum 31: 315-24, 1988.

17. Fries JF, Spitz P, Kraines RG, Holman HR: Measurement of patients outcome in arthritis. Arthritis Rheum 23: 137-45, 1980.

18. Ferraz MB, Oliveira LM, Araújo PM, Atra E, Tuqwell P: Crosscultural reliabilty of the physical ability dimension of the heath assessment questionnaire. J Rheumatol 17: 813-7, 1990.

19. Sharp JT, Bluhm GB, Brook A, et al.: Reproducibility of multiple observer scoring of radiologic abnormalities in the hands and wrists of patients with rheumatoid arthritis. Arthritis Rheum 28: 16-24, 1985.

20. Berquó ES, Souza JMP, Gotlieb SLD: Bioestatística. São Paulo: EPU, 1981.
21. Morettin P, Bussab W: Estatística Básica. São Paulo: Atual, 1982.

22. Siegel S: Estatística não paramétrica. São Paulo: ED. McGrawHill do Brasil, 1981.

23. Kleinbaum DG, Kupper LL, Muller KE, Nizam A: Applied regression analysis and other multivariable methods. Belmont: Duxbury Press, 1998.

24. Hürlimann D, Enseleit F, Ruschitzka F: Rheumatoid arthritis, inflammation, and atherosclerosis. Herz 29: 760-8, 2004.

25. Kroot EJ, de Jong BA, van Leeuwen MA, et al.: The prognostic value of anti-cyclic citrullinated peptide antibody in patients with recent-onset rheumatoid arthritis. Arthritis Rheum 43: 1831-5, 2000.

26. Schellekens GA, Visser H, de Jong BAW, et al.: The diagnostic properties of rheumatoid arthritis antibodies recognizing a cyclic citrullinated peptide. Arthritis Rheum 43: 155-63, 2000.

27. Goldbach-Mansky R, Lee J, McCoy A, et al.: Rheumatoid arthritis associated autoantibodies in patients with synovitis of recent onset. Arthritis Res 2: 236-43, 2000.

28. Silva AF, Matos AN, Lima AMS, Lima EF, Correa ICC, Carvalho EM: Associação do Anticorpo Anti-citrulina e Gravidade da Artrite Reumatóide. Rev Bras Reumatol 46: 165-73, 2006.

29. Santos WS, Fernandes ARC, Silva NP, Atra E, Andrade LEC: Significado clínico do fator perinuclear e anticorpo antiestrato córneo na artrite reumatóide. Rev Bras Reumatol 37: 309-16, 1997.

30. Araújo FAGR, Gabriel JA, Assad RL, Quaresma M, Perez S, Atra E: Fator Von Willwbrand e de doenças reumáticas: marcador de lesão vascular ou reagente de fase aguda? Rev Bras Reumatol 35: 247-52, 1995.

31. Klimiuk PA, Sierakowiski S, Latosiewicz R, et al.: Soluble adhesion molecules (ICAM-1, VCAM-1, and E-selectin) and vascular endothelial growth factor (VEGF) in patients with variants of rheumatoid synovitis. Ann Rheum Dis 61: 804-9, 2002.

32. Dolezalová $P$, Telekesová $\mathrm{P}, \mathrm{Nenscová} \mathrm{D}$, Belosová J, Kvasnicka J, Hoza J: Laboratory indicators of endothelial involvement in rheumatic diseases associated with vasculitis in children. Cas Lek Cesk 142: 615-9, 2003.

33. Klimiuk PA, Sierakowski S, Fiedorczyk M, Chwiecko J: Serum tumor necrosis factor alpha (TNF-alpha) concentration correlates with soluble adhesion molecules and vascular endothelial growth factor (VEGF) in rheumatoid arthritis. Przegl Lek 61: 86-9, 2004.

34. Ugur M, Yildirim K, Kiziltunc A, Karatay S, Senel K: Correlation between soluble intercellular adhesion molecule 1 level and extracellular superoxide dismutase activity in rheumatoid arthritis: a possible association with disease activity. Scand J Rheumatol 33: 239-43, 2004. 